Volume 9, No.1, January - February 2020

International Journal of Advanced Trends in Computer Science and Engineering

Available Online at http://www.warse.org/IJATCSE/static/pdf/file/ijatcse60912020.pdf

https://doi.org/10.30534/ijatcse/2020/60912020

\title{
A Triaxial Model for the Digital Maturity Diagnosis
}

\author{
Fadwa Zaoui ${ }^{1}$, Nissrine Souissi ${ }^{2}$ \\ ${ }^{1}$ EMI-SIWEB team Mohammed V University, Morocco, fadwa.zaoui@gmail.com \\ ${ }^{2}$ Computer Science department, ENSMR, Morocco, souissi@enim.ac.ma
}

\begin{abstract}
Digital transformation is a strategic transformation process, built on two main founding bases; firstly, identifying the dimensions of a company's digital transformation, secondly, the digital pre-transformation multidimensional assessment. This paper introduces the development of a multidimensional digital pre-transformation valuation system, proposing to start this exercise by assessing the ICT dimension. The approach adopted in this work consists in identifying the evaluation criteria, defining measurement tools for these criteria, in order to deduce the ICT maturity levels. The findings present a triaxial ICT assessment model. The model axes are access, content and use. These axes represent the criteria to be qualified, by a questionnaire, in order to identify the ICT maturity level of a company.
\end{abstract}

Key words: Digital transformation, ICT, Assessment Model, Maturity Model, Information Technology.

\section{INTRODUCTION}

Due to its socio-economic challenges, Digital transformation (DT) is one of the topics of most concern to the international community. In particular the researchers, who are trying to elucidate this concept in order to provide all stakeholders with the elements necessary to carry out a digital transformation.

Several definitions of DT are proposed in the literature, and generally result from a precise perception of DT, in particular [1]:

- The technological vision, defining DT by the use of new digital technologies;

- The organizational vision, defining DT by organizational transformation and the creation of new business models;

- The social vision, defining DT by all of the digital phenomena influencing the individual lives.

We define DT by a new development model, which calls for the re-definition of the product and service offer [2] and the relationship of the company to its customers, through a multidimensional business transformation process.
The multidimensional aspect of this transformation was the subject of previous work [3], which allowed the identification of the dimensions of a DT, namely:

- Structural Dimension: Involves changing the organizational structure, processes and skills needed to exploit new technologies;

- Informational Dimension: Involves data/information management;

- Environmental Dimension: Includes macro-environmental factors influencing ICT integration (Regulatory Framework, Resources);

- Security Dimension: Includes; IT security (hardware, application and network), data and human security and environmental security;

- Quality Dimension: Consists of the quality of the product and service resulting from Digital Transformation;

- Financial Dimension: Consists of investment / return on investment;

- Cultural Dimension: Consists of all the values and behaviors shared by a community / ICT Culture;

- Innovation Dimension: Includes innovation in technology design, technology processes and ICT Management;

- Participative Dimension: Consists of the collaboration/interaction of any stakeholder, including the user.

In fact, thinking about the DT of a company presupposes a study of what already exists, which must cover all the aforementioned dimensions. We believe that the assessment of these dimensions is a prerequisite for the definition of a DT roadmap.

It is commonly recognized that the key dimension of TD is the environmental one, precisely in its technical and technological components $[4,5,6,7,8]$. In the rest of this paper, we will designate the environmental dimension by the term ICT (Information and Communication Technology).

In this paper, we discover the pre-DT assessment field practices through a case study, before launching a reflection on the pre-DT evaluation systems initiated by the assessment of the ICT component by proposing an assessment model. 
This paper is organized into 5 sections. After introducing the context of this paper, we present in the second section the multidimensional nature of the DT, before focusing on the ICT aspect. Subsequently, in the third section, we use a case study to identify the main gaps of pre-TD evaluation practices on the ground, which we are trying to overcome by proposing an ICT assessment model, within the framework of a multidimensional pre-digitalization evaluation system, presented in the fourth section. We conclude in the fifth section with a sum-up of the key points of the paper and its potential perspectives.

\section{ICT AND Digital Transformation}

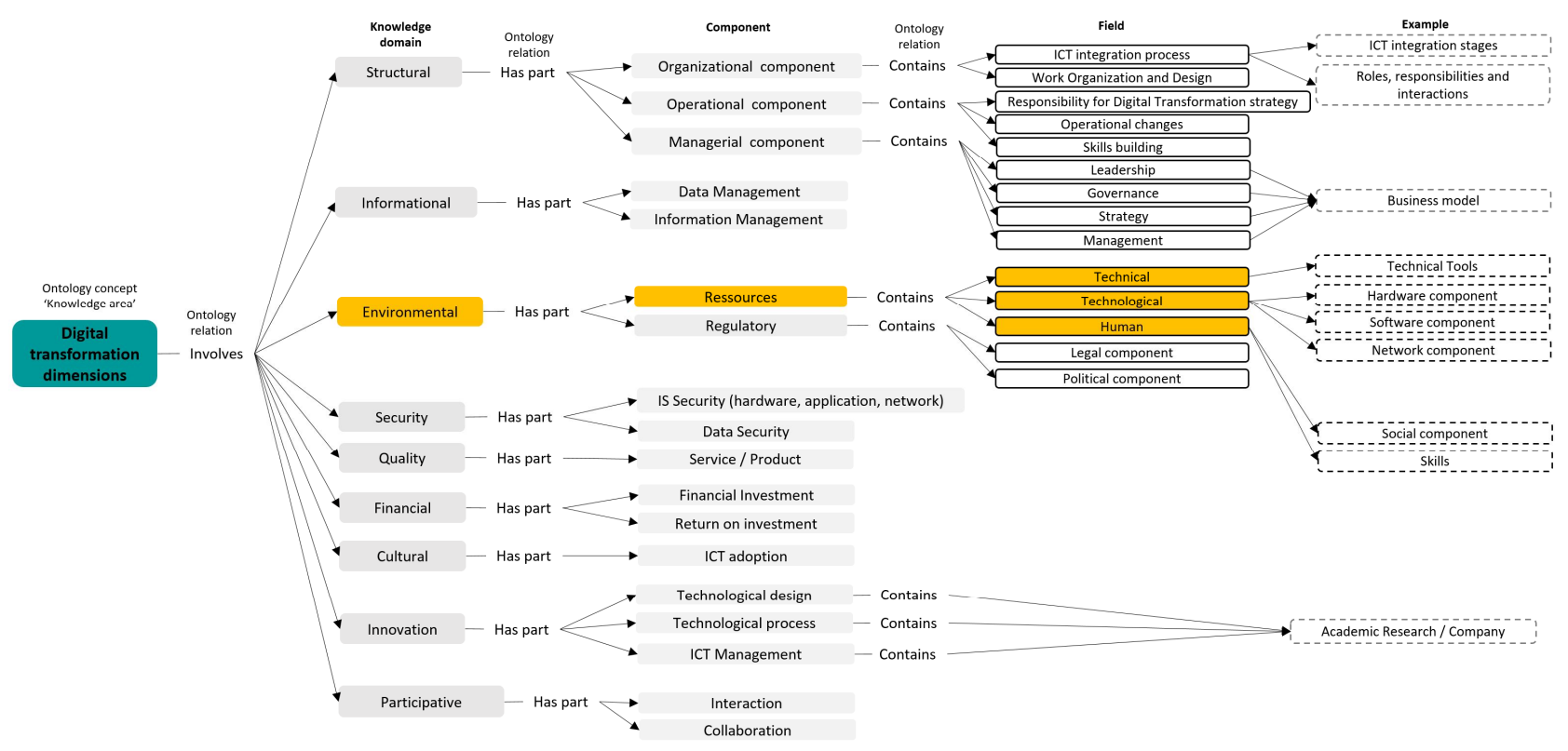

Figure 1: Ontology-Based Model for Digital Transformation's knowledge [3].

In the paper [9], we explain that companies tend to think of DT from the only perspective of improving the cost-profit ratio, focusing solely on the introduction of ICT into existing processes. Rather than radical, multidimensional changes, companies make small-scale attempts by IT adopting. Which imply failing to consider DT as a coherent strategic transformation process to be applied as a whole [10], involving that the concrete benefits are lacking.

Nevertheless, by alerting the companies to this widespread restrictive technological vision, we do not discredit this dimension, but we qualify the perception customary made of it. ICTs are indeed the cornerstone of DT, but as a necessary, but not sufficient, component of DT.

According to the ontology, the dimension covering ICTs is the environmental one, including the macro-environmental
This section deals with the different dimensions on which DT should be based, with a focus on the ICT component, as we aim to evaluate it in this work.

In the paper [3], we explain our transverse vision of DT, covering the several aspects of the company identified in the context of this work and from which result the ontology of DT presented in Figure 1.

We encourage companies to adopt this vision in order to seize the economic opportunity of DT, to thwart a general trend, from the debate on DT that we consider problematic: the media craze and the focusing on technology leads to lose sight of the concrete economic utility of DT. 
Indeed, and as explained in the previous section, it is common in the professional environment to restrict DT to ICT integration, which implies that any initiative to assess the existing preceding such transformation, is limited to the ICT diagnosis.

The case presented in the following has been studied in-depth in paper [9], and confirms this observation in the context of a Moroccan industry.

\subsection{Factory presentation}

For confidentiality reasons, the studied industry will be referred in the following by Factory. It was founded in 1997 in Morocco. Its main activity is to manufacture and market sugar and chocolate confectionery. It currently has more than $15,000 \mathrm{~m}^{2}$ of modern manufacturing facilities, storage and shipping of a wide range of products. With an average production capacity of 12 tons/day and a workforce of 250 employees, Factory is the leader in its sector.

\subsection{Pre-DT assessment}

Digital transformation is a project entirely led by the IT team. The study of the existing consists of the study and the evaluation of the infrastructure and the operating IT.

Factory's industrial communication infrastructure is arranged in a star-shaped layout, all machines located in industrial plants communicate via the Profibus protocol with a master PLC that is connected to a server via the Profinet protocol.

Each product is cooked in a cooker fed by raw material tanks controlled by "Gravomats". Siemens PLCs that execute instructions ordered according to the predefined recipe in turn control "Gravomats".

The PLCs are used to collect data, namely process parameters (cooking temperature, pressure, etc.), states (on/off) and meters (number of pieces produced) trough sensors installed on each cooker. The collected data is sent by the Profibus protocol to secondary PLCs (slaves) to be finally routed to a Master PLC directly linked to a server by a Profinet, processing them according to Factory's business needs.

Factory has a customized MES covering the features bellow:

- Production monitoring reports generation ;

- KPI Visualization: MTBF, Efficiency, TRS, hour rate, \% PP gap ;

- Real-time monitoring of different process parameters;

- Material consumption monitoring ;

- Qualification of major stops ;

- Control command system.

Concerning the MES limitations, it is mainly because of the high development cost and time, random and unstructured updates, lack of connection with the ERP.
As for the infrastructure's limitations, it is essentially its cumbersome aspect, no control/no correction of stored data, and incompatibility with Siemens MindConnect.

\subsection{Results Analysis}

Two key findings can be raised from the case of Factory's pre-DT assessment, assuming that we only evaluate the ICT component, namely:

- There is no prior framing of the ICT components to be considered in the evaluation exercise;

- The evaluation relates systematically to an existing production process, which the company aims to improve using the technological tool.

The diagnosis consists in identifying a production link with deficiencies, and injecting ICT tools to remedy these.

This observation is predominant in the professional place. If with such assessments companies succeed in taking corrective actions, in the short term and on a small scale, nevertheless, they miss the opportunity to structure a constructive ICT integration process, resulting itself from a strategic DT process.

Based on this observation, we consider it relevant to start the multidimensional evaluation exercise of a company's predisposition to conduct a DT, by the ICT / technical and technological component, which is an assertive reality in any Digital perception in companies.

\section{ICT ASSESSMENT MODEL}

Every company that want to think about its digitalization should assess its existing in terms of DT dimensions/sub-dimensions, identified in the ontology.

The purpose of the multidimensional pre-DT diagnosis is to situate the company in the digital field and to define a DT tailor-made strategy, which takes into account the context, the resources, the needs and the objectives of the company. Hence, Assessment is not only a challenge to complete [11] but conditions the approach and the success of a DT [12]. It is therefore important to support companies in this exercise by providing them with a multidimensional assessment system $[12,13]$.

For the aforementioned reasons, justifying the interest in ICT in the context of a DT, whether in the scientific or professional environment, the pre-DT diagnostic exercise is initiated by the assessment of this component (provided we evaluate the other dimensions mentioned above).

The approach adopted for this work is based on the steps described in Figure 2 [14, 15]: 

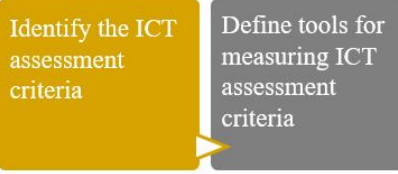

Seed in maturity levels

Evaluate ICT

maturity in the ground
Figure 2: Four step procedure to assess ICT maturity

Referring to the paper [16], dealing with a platform readiness evaluation, on the ICT level, to carry out a Smart City project, the determining criterions compatible with this assessment work, are the following:

Use: consists of the meatware, being human entities that operate or use ICT.

Content: integrates software content/application set, allowing the user to access to data and services.
Access: to ICT is achieved through the infrastructure/infostructure (hardware and network) integrating telecommunication technologies as well as electronic and mechanical technologies related to ICT [17].

Once the axes of ICT evaluation identified, we used the DT-ontology in order to establish the detailed components of every axe. In result, we obtained a triaxial model, presented in Figure 3 [18], that we developed based on the notation explained in [19] and previously used at the onto-DT [3].

This guidance model interest is to enable a company to define the ICT evaluation criteria's elements. It is about drawing up an ICT inventory and its appraisal that any company that undertake a DT should establish. It is indeed a key step to ascertain the ICT initial speed of the company.

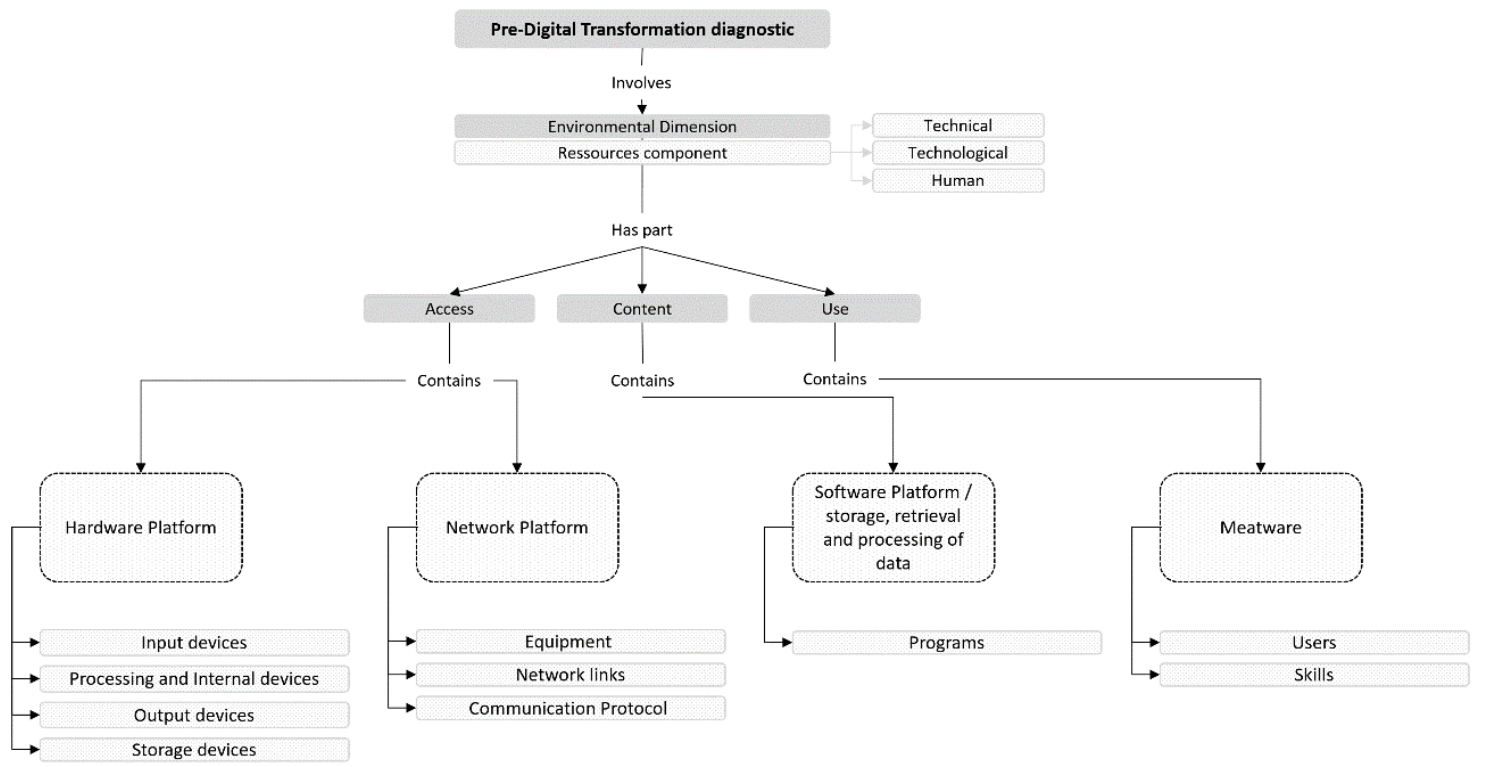

Figure 3: ICT assessment model.

To determine a company's positioning in relation to the criteria previously identified in Figure 3, we propose to use a measure tool $[13,15]$ of the different ICT components. It is about submitting the questionnaire presented in Table 1 to companies. These questions are proposed for guidelines purpose only [20] and can be enriched according to company's activity sector.

The ICT potential differs from one company to another, and depends obviously on its ICT capital. Hence, the interest of this evaluative questionnaire, the answers to these questions enable to level the ICT maturity [21]. Indeed, we propose to collect these responses from stakeholders, and use them to identify the level of ICT inclusion in a company. Accordingly, and based on the management rules explained in table 2, an ICT three-level maturity grid can be proposed: low, moderate or high ICT maturity level. 
Table 1: ICT maturity questionnaire.

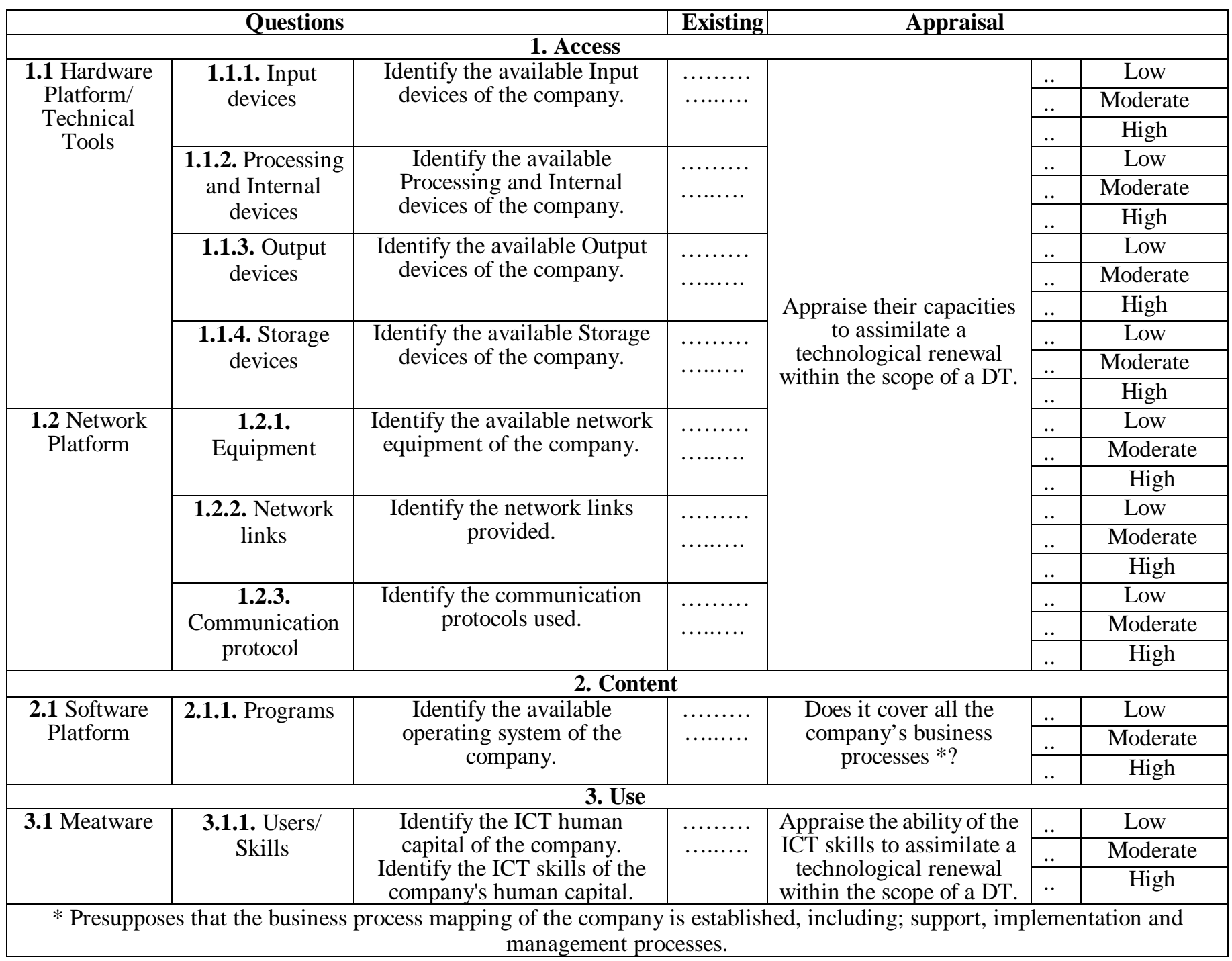

Table 2: ICT maturity level grid.

\begin{tabular}{|l|c|c|c|}
\hline \multirow{4}{*}{$\begin{array}{l}\text { ICT maturity } \\
\text { level } \\
\text { management } \\
\text { rules }\end{array}$} & $\begin{array}{c}\text { If the number of 'Low' responses } \\
\text { obtained is dominating }\end{array}$ & $\begin{array}{c}\text { 'Low' ICT maturity } \\
\text { level }\end{array}$ & $\begin{array}{c}\text { ICT system must be reviewed in the case of } \\
\text { technological renewal resulting from DT }\end{array}$ \\
\cline { 2 - 4 } & $\begin{array}{c}\text { If the number of 'Moderate' } \\
\text { responses obtained is } \\
\text { dominating }\end{array}$ & $\begin{array}{c}\text { 'Moderate' ICT } \\
\text { maturity level }\end{array}$ & $\begin{array}{c}\text { ICT system must be upgraded in the case of } \\
\text { technological renewal resulting from DT }\end{array}$ \\
\cline { 2 - 4 } & $\begin{array}{c}\text { If the number of 'Moderate' } \\
\text { responses obtained is } \\
\text { dominating }\end{array}$ & $\begin{array}{c}\text { 'High' ICT } \\
\text { maturity level }\end{array}$ & $\begin{array}{c}\text { The ICT system can support in the case of } \\
\text { technological renewal resulting from DT } \\
\text { * provided to identify the improvement areas. }\end{array}$ \\
\hline
\end{tabular}


Outside of this study, and with the aim to gauge the ICT maturity of a company in the field belonging to an emerging bank, that wants to launch a reflection on a DT strategy. In Table 3, we do not detail the ICT capital of this bank, which was able to establish an ICT inventory using this questionnaire. Nevertheless, we submitted this questionnaire to an ICT manager; from the banking sector and we resume in the following the appraisal made of it.

The assessment exercise is a prerequisite for any evolving process that a company may launch. The one interesting us consists of the DT, which requires a multidimensional appraisal of the company, namely the ICT dimension.

It is precisely the purpose of this section, to identify the ICT maturity level through an ICT evaluation grid. The ICT maturity level is considered the first 'input' feeding the reflection on the company's DT strategy that must be completed by the other 'inputs' resulting from the evaluation of the other dimensions.

Table 3 :. Exemple d'évaluation ICT.

\begin{tabular}{|c|c|c|c|c|c|c|c|c|}
\hline \multirow[t]{3}{*}{ Input devices } & $\sqrt{ }$ & Low & \multirow[t]{3}{*}{ Storage devices } & $\checkmark$ & Low & \multirow{3}{*}{$\begin{array}{l}\text { Communication } \\
\text { protocol }\end{array}$} & & Low \\
\hline & & Moderate & & & Moderate & & $\sqrt{ }$ & Moderate \\
\hline & & High & & & High & & & High \\
\hline \multirow{2}{*}{$\begin{array}{l}\text { Processing and } \\
\text { Internal devices }\end{array}$} & & Moderate & \multirow{2}{*}{ Equipment } & $\checkmark$ & Moderate & \multirow{2}{*}{ Programs } & & Moderate \\
\hline & & High & & & High & & & High \\
\hline \multirow[t]{2}{*}{ Output devices } & $\checkmark$ & Low & \multirow[t]{2}{*}{ Network links } & & Low & \multirow[t]{2}{*}{ Users/ Skills } & & Low \\
\hline & & High & & & High & & & High \\
\hline
\end{tabular}

Result: Most of the ICT components are considered of 'Low' capacity to support technological renewal within the scope of a DT. The entire ICT system must be reformed in the process of the DT strategic transformation.

\section{CONCLUSION}

Our reflection on DT is based on three main interdependent and sequential lines of thinking, namely: the identification of DT dimensions of a company, the multidimensional pre-DT assessment, and the setting up of a multidimensional DT process.

Regarding the second axe, this paper initiates the building up of a multidimensional pre-DT assessment system, in a decomposed way, as it proposes to treat the topic starting by the analysis of the ICT assessment components, using a triaxial model, from which ensue an ICT assessment questionnaire and an ICT maturity grid.

This work is considered as a first step of the evaluation process that should imperatively be completed by the appraisal of the other DT dimensions. Ideally, the correlation of several assessment models set up by dimension can lead to establish the multidimensional pre-DT assessment system mentioned before. Which is a prerequisite to set up a multidimensional roadmap/process to DT.

\section{REFERENCES}

1. Reis, J., Amorim, M., Melão, N., and Matos, P. Digital transformation: a literature review and guidelines for future research. In World Conference on Information
Systems and Technologies, pp. 411-421. Springer, Cham, 2018.

2. Parviainen, P., Tihinen, M., Kääriäinen, J., and Teppola, S. Tackling the digitalization challenge: How to benefit from digitalization in practice. International journal of information systems and project management, 5(1), 63-77, 2017.

3. Zaoui, F., Souissi, N. OntoDigital: An Ontology-Based Model for Digital Transformation's Knowledge, International Journal of Information Technology and Computer Science (IJITCS), Vol.10, No.12, 2018, pp.1-12. DOI: 10.5815/ijitcs.2018.12.01, 2018.

4. Agarwal, R., Gao, G., DesRoches, C., and Jha, A. K. The digital transformation of healthcare: status and the road ahead. Information Systems Research, 21(4), 796-809, 2010.

5. Rüßmann, M., Lorenz, M., Gerbert, P., Waldner, M., Justus, J., Engel, P., and Harnisch, M. Industry 4.0: The future of productivity and growth in manufacturing industries. Boston Consulting Group, 9(1), 54-89, 2015.

6. Lee, J., Bagheri, B., and Kao, H. A. A cyber-physical systems architecture for industry 4.0-based manufacturing systems. Manufacturing letters, 3, 18-23, 2015.

7. Erol, S., Schumacher, A., and Sihn, W. Strategic guidance towards Industry 4.0-a three-stage process model. In International conference on competitive manufacturing. Vol. 9, No. 1pp. 495-501, 2016. 
8. De Carolis, A., Macchi, M., Negri, E., and Terzi, S. Guiding manufacturing companies towards digitalization a methodology for supporting manufacturing companies in defining their digitalization roadmap. In 2017 International Conference on Engineering, Technology and Innovation (ICE/ITMC), pp. 487-495. IEEE, 2017.

9. Zaoui, F., Assoul, S., and Souissi, N. What Are the Main Dimensions of Digital Transformation? Case of an Industry. International Journal of Recent Technology and Engineering (IJRTE) ISSN: 2277-3878, Volume-8 Issue-4, November 2019. DOI: 10.35940/ijrte.D4418.118419, 2019.

10. Davis, E. B., Kee, J., and Newcomer, K. Strategic transformation process: Toward purpose, people, process and power. Organization Management Journal, 7(1), 66-80, 2010.

11. http://www.ausimaroc.com/wp-content/uploads/2019/09 /La-Transformation-Digitale-Au-Maroc-Livre-Blanc-20 19.pdf

12. Berghaus, S., and Back, A. Stages in Digital Business Transformation: Results of an Empirical Maturity Study. In MCIS. p. 22, 2016.

13. De Bruin, T., Freeze, R., Kaulkarni, U., and Rosemann, $\mathrm{M}$. Understanding the main phases of developing a maturity assessment model, 2005.
14. Schumacher, A., Erol, S., and Sihn, W. A maturity model for assessing Industry $\mathbf{4 . 0}$ readiness and maturity of manufacturing enterprises. Procedia Cirp, 52, 161-166, 2016. https://doi.org/10.1016/j.procir.2016.07.040

15. Gill, M., and VanBoskirk, S. The digital maturity model 4.0. Benchmarks: Digital Transformation Playbook, 2016.

16. Zaoui, F., and Souissi, N. ICT assessment axes for the smart city approach. In Proceedings of the Mediterranean Symposium on Smart City Application. P. $8 . \quad$ ACM. https://doi.org/10.1145/3175628.3175631, 2017.

17. Malek, J. A. Informative global community development index of informative smart city. In Proceedings of the 8th WSEAS International Conference on Education and Educational Technology. Pp. 17-19, 2009.

18. https://www.techopedia.com/

19. http://www.bimframework.info/2015/08/bim-ontology.h tml.

20. https://www.onlineauthority.com/blog/technology-resou rces-dimension/

21. Poeppelbuss, J., Niehaves, B., Simons, A. and Becker, J. Maturity Models in Information Systems Research: Literature Search and Analysis, Communications of the Association for Information Systems: Vol. 29, Article 27. DOI: 10.17705/1CAIS.02927, 2011. 